\title{
DEGENERATIVE STENOSIS OF THE LUMBAR SPINE
}

Sérgio Zylbersztejn' ${ }^{1}$, Leandro de Freitas Spinelli ${ }^{2}$, Nilson Rodinei Rodrigues ${ }^{3}$, Pablo Mariotti Werlang ${ }^{4}$, Yorito Kisaki ${ }^{5}$, Aldemar Roberto Mieres Rios ${ }^{6}$, Cesar Dall Bello ${ }^{7}$

\section{ABSTRACT}

This paper presents an update on degenerative stenosis of the lumbar spine, which is a common pathological condition among patients over the age of 65 years. The anamnesis and physical examination need to be precise, since radiography often only provides indirect signs. Magnetic resonance imaging is necessary if the symptoms persist. The treatment for lumbar stenosis is a matter of controversy. However, there seems to be some benefit from surgical treatment rather than conservative treatment, such that surgery brings improvements in symptoms and functions for a period of up to two years.

Keywords - Spine/pathology; Spine/radiography; Spinal Stenosis

\section{INTRODUCTION}

Lumbar stenosis is a frequent disorder that occurs in elderly patients, and it is also a reason for surgical indications at advanced ages ${ }^{(1)}$. Spinal stenosis results from narrowing of the canal, which causes confinement of the neural structures by the bones of the spine and adjacent soft tissue ${ }^{(2)}$. The difficulty in this anatomical designation lies in the fact that the narrowing is necessary for diagnosing the pathological condition, but may not be sufficient to determine the severity of the symptoms and the functional alterations that lead the patient to be treated. Severe anatomical stenosis may be present even in asymptomatic patients $^{(3)}$. In general, the symptoms start slowly and gradually. However, they may be exacerbated through trauma and intense activity ${ }^{(4)}$.

Stenosis can be classified as primary, caused by congenital abnormalities or developed postnatally; or secondary, resulting from degenerative alterations or as a consequence of infection, trauma or surgery ${ }^{(3)}$. Degenerative stenosis may involve the central canal, the lateral recess, the foramens, or a combination of these, and is the commonest cause of acquired stenosis, which especially affects adults and elderly people $^{(1,5)}$. There has been a continual increase on life expectancy, thus resulting in a concomitant increase in occurrences of this condition. Although the exact incidence is unknown, it has been estimated that lumbar stenosis affects between three and twelve patients for every 100,000 inhabitants per year over the age of 65 years $^{(5,6)}$.

The natural history of stenosis remains challenging. The existence of triarticulate mobility as a functional unit and its close contact with neural structures, along with the existence of a main avascular structure (the intervertebral disc), are the factors responsible for this pathological condition ${ }^{(1)}$. Central stenosis results from a decrease in the canal

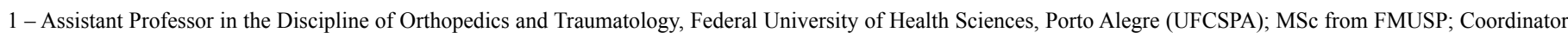
of the Orthopedic Spinal Surgery Service, Santa Casa de Porto Alegre Hospital Complex (CHSCPA), Porto Alegre, RS, Brazil.

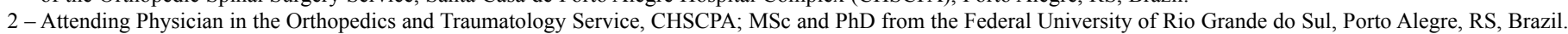

3 - PhD in Orthopedics and Traumatology from FMUSP; Head of the Spine Sector, Santo Antônio Children's Hospital, CHSCPA, Porto Alegre, RS, Brazil.

4 - Fellowship in Spinal Surgery at Leopoldina Hospital, Germany; Instructor in the Spine Group, CHSCPA, Porto Alegre, RS, Brazil.

5 - PhD in Spinal Surgery from the University of Sapporo, Hokkaido, Japan; Head of the Adult Spine Sector, Hospital Santa Clara, CHSCPA, Porto Alegre, RS, Brazil.

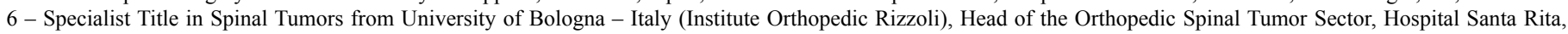
CHSCPA, Porto Alegre, RS, Brazil

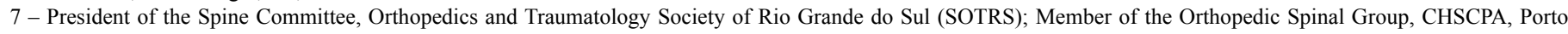
Alegre, RS, Brazil.

Work performed at the Orthopedic Spinal Surgery Service, Santa Casa de Porto Alegre Hospital Complex (CHSCPA), Porto Alegre, RS

Correspondence: Rua Dr. Florencio Ygartua 270-702, Independência, 90430-010 Porto Alegre, RS. E-mail: sergiozyl@gmail.com

Work received for publication: November 3, 2011; accepted for publication: November 3, 2011.
}

The authors declare that there was no conflict of interest in conducting this work 
diameter anteroposteriorly, transversally or a combination of these, secondarily to loss of disc height, annulus lesion and osteophyte formation, thus leading to instability that gives rise to hypertrophy of the facets and the yellow ligament ${ }^{(3)}$. Degeneration of the intervertebral discs causes decreased relative stability and for this reason, facet hypermobility occurs ${ }^{(4)}$. A study on cadavers suggested that pressure on the facets increases with decreasing disc height and with extension of the spine ${ }^{(7)}$. This would lead to hypertrophy of the facet joints, especially at the upper joint process. Because of this degeneration, calcification and hypertrophy of the yellow ligament occur. The final result is reduction of the dimensions of the canal and compression of the neural elements ${ }^{(4,7)}$.

Fibrosis is the main cause of hypertrophy of the yellow ligament, and this is caused by the accumulated mechanical stress. The same process occurs with the lateral recess and the foraminal space. Foraminal stenosis frequently affects the root of L5, given that L5S1 is the level with the lowest foramen/ nerve root ratio $^{(3)}$.

In relation to clinical characteristics, central stenosis causes neurogenic claudication. On the other hand, foraminal stenosis correlates with radiculopathy ${ }^{(4)}$. Ciric et $\mathrm{al}^{(8)}$ observed that facet arthritis was the commonest cause of stenosis in this region, in conjunction with pathological conditions of the disc.

Canal stenosis occurs most frequently at the L4L5 level, followed by L5S1 and L3L4 ${ }^{(4,6)}$. However, attention needs to be paid to the possibility of disc herniation, spondylolisthesis, spondylolysis and Paget's disease, which exacerbate the narrowing ${ }^{(1,4)}$. It should be borne in mind that spondylolysis and spondylolisthesis in young patients do not cause stenosis of the vertebral canal ${ }^{(4)}$.

Lumbar stenosis also presents a dynamic component. The canal space decreases with extension and increases with axial distraction and flexion ${ }^{(9)}$. In the case of the foramens, flexion increases their area by $12 \%$ and extension decreases it by $15 \%{ }^{(10)}$.

\section{Clinical characteristics}

Complaints of sciatic pain occur in up to $95 \%$ of the cases and neurogenic claudication in up to $91 \%^{(2,3,11)}$. Sensory alterations in the lower limbs are present in $70 \%$, motor losses in $33 \%$ and bilateral symptoms in up to $42 \%$. Patients often report lumbalgia and chronic sciatic pain ${ }^{(4)}$. Lower-limb disorders like fatigue, feelings of heaviness in the legs and paresthesia, and also neurogenic bladder and cramps, are frequently reported. The symptoms may be unilateral, but they are generally bilateral and symmetrical ${ }^{(3)}$.

Regarding symptom distribution, L5 is affected in $91 \%$ of the cases, S1 in $63 \%$, L1-L4 in $28 \%$ and S2-S5 in 5\%, and $47 \%$ of the patients may present symptoms in two nerve roots, $17 \%$ in three levels and $1 \%$ in four. In the case of central stenosis, the symptoms are generally bilateral, while in stenosis of the lateral recess, they are related to the dermatome affected. In the former, patients will more often report difficulty in walking, while in the latter, there will more often be pain while resting and at night ${ }^{(1,3,4)}$.

Patients should be assess in such a way as to rule out the differential diagnoses, among which the ones most frequently encountered are vascular abnormalities, which can be differentiated from stenosis of acute or chronic nature. Among the acute conditions that may simulate cauda equina syndrome are rupture of the abdominal aorta, aneurysms of the iliac, dissection of the aorta, acute ischemia in the lower limbs and deep vein thrombosis. Among the chronic diseases is arterial insufficiency, which causes intermittent ischemia that more resembles neurological problems. The presentation of discomfort and pain in the lower limbs while walking can be well differentiated between the two pathological conditions ${ }^{(1)}$. In neurogenic claudication, patients can lessen their symptoms through flexing the trunk; they present better performance in going up stairs and cycling; the peripheral pulses are always present; the skin is normal; and the lumbalgia is "routine". All of these differ from vascular claudication ${ }^{(4)}$.

The neurological examination tends to be normal, but abnormalities may be seen if patients are asked to walk such that they are at the limit of discomfort. In some cases, indications of motor weakness or sensory abnormalities may be found ${ }^{(3,4)}$. Lasègue's test is generally absent, thus differentiating stenosis from disc hernia. Lumber extension may cause discomfort, and this is relieved through flexion ${ }^{(5)}$. The symptoms may worsen or improve through sitting down, and the distances that can be walked without pain may vary from day to day. Bladder and intestinal dysfunctions should be assessed ${ }^{(6)}$. 


\section{Radiographs}

Differing from patients with advanced gonarthrosis or coxarthrosis, some of these patients are asymptomatic, even with images showing significant joint degeneration ${ }^{(1)}$. Disc degeneration, facet osteoarthritis and osteophytes may be found in 90 to $100 \%$ of the patients over the age of 64 years ${ }^{(6,12,13)}$. Myelography may show lumbar stenosis in up to $6 \%$ of the patients within this age group, and this is a common finding in up to $80 \%$ of the patients over the age of 70 years $^{(6)}$. However, radiographic evidence of stenosis is often inconspicuous, and clinical correlation is necessary ${ }^{(2)}$. Radiographs do not confirm the diagnosis of stenosis, but they may show indications, such as short pedicles in lateral view, narrowing of the pedicles in anteroposterior view (clip sign), calcification of the ligaments, narrowing of the foramens and hypertrophy of the joint facets (Figure $1 \mathrm{~A}, \mathrm{~B}$ and $\mathrm{C}$ ). Radiographs produced in extension and in flexion are useful for identifying preexisting instability, before indicating a surgical procedure. Translation of more than $4 \mathrm{~mm}$ or rotation of more than $10^{\circ}$ indicates instability ${ }^{(4)}$. Punjabi presented the following parameters for identifying lumbar instability: displacement in the sagittal plane $>4.5 \mathrm{~mm}$ or $15 \%$ and a relative angle in the sagittal plane of $22^{\circ}$.
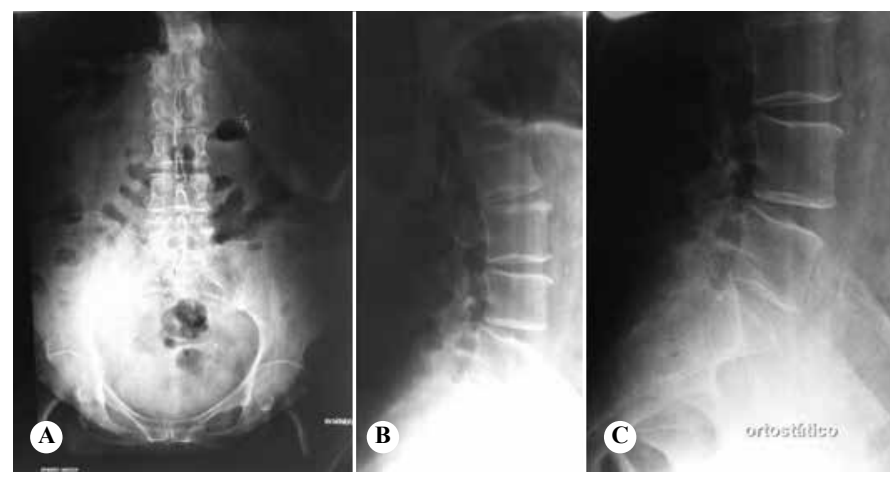

Figure 1 - Radiograph on an 82-year-old patient presenting lumbar sciatic pain and progressive claudication. (A) Anteroposterior; (B) lateral; (C) focused lateral.

\section{Magnetic resonance}

Abnormalities on magnetic resonance imaging (MRI) do not always correlate with the symptoms: they may be present in asymptomatic patients and they range from 20 to $67 \%{ }^{(6,15,16)}$. In patients over the age of 60 years, $57 \%$ of MRI shows abnormalities, including disc hernias (36\%) and stenosis (21\%). MRI may provide elucidation in diagnosing symptomatic patients, but should not be a screening examination for reasons already discussed ${ }^{(4)}$. The canal size may be the sole component in the pathogenesis of symptomatic stenosis, which causes compression of the canal content, especially the neural and vascular structures (Figure $2 \mathrm{~A}$ and $\mathrm{B}$ ). If there is no compression, the canal should only be described as narrow, and not as stenosed ${ }^{(1,6)}$.

T2 images are of interest because they present similarities with myelograms. Absence of fat surrounding the nerve roots indicates foraminal stenosis, especially on $\mathrm{T} 1$ images. This examination has the disadvantage of its cost, but it is an excellent noninvasive tool ${ }^{(1,5,6,17)}$.

MRI is the most appropriate noninvasive imaging examination for diagnosing degenerative stenosis. In the case of patients with contraindications against MRI, or for those whose findings are inconclusive or those in whom there is a poor correlation between the symptoms and the MRI findings, myelotomography becomes the preferred examination ${ }^{(17)}$.

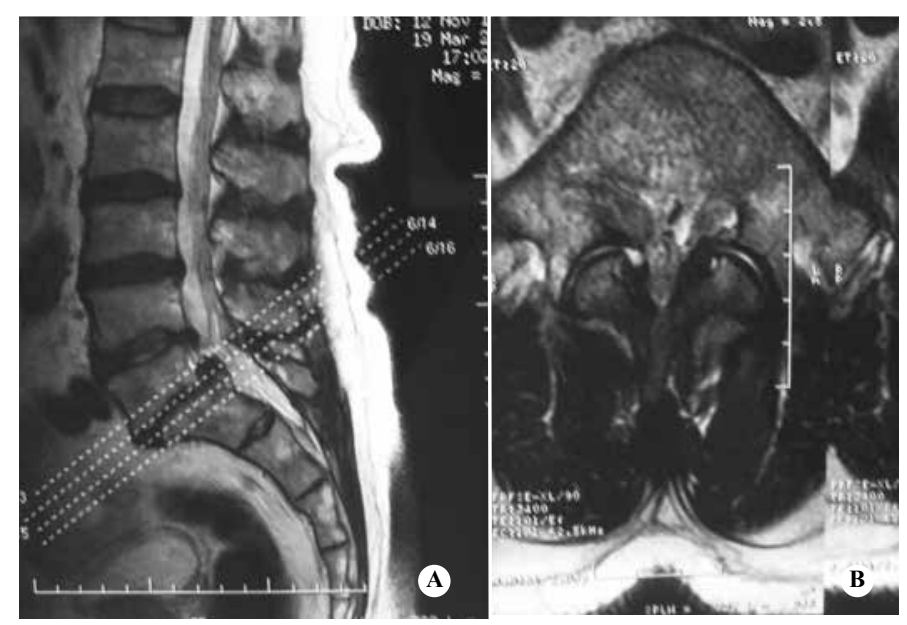

Figure 2 - Magnetic resonance imaging showing lumbar stenosis: (A) sagittal slice presenting diseased disc and thickening of the yellow ligament; and (B) axial slice illustrating thickening of the yellow ligament and medullary distress.

\section{Myelotomography and computed tomography}

Myelography followed by computed tomography (CT) continues to be used in surgical planning for stenosis treatment, with accuracy of $91 \%$. This examination is indicated for patients with dynamic stenosis, sciatica after a surgical procedure, severe scoliosis, severe spondylolisthesis, metal implants, contraindications against MRI or symptoms in the absence of MRI abnormalities ${ }^{(4)}$.

Eun et $\mathrm{l}^{(18)}$ conducted a study comparing lumbar 
stenosis seen on CT and MRI, and they observed that greater narrowing of the canal was found on CT. They discussed whether this was due to the greater capacity of CT for discriminating bone tissue from soft tissue, such as the yellow ligament. In their conclusion, they emphasized the value of combined examination with MRI before the surgical procedure.

Wiesel et $\mathrm{al}^{(19)}$ evaluated 52 asymptomatic patients by means of CT and observed abnormalities in $50 \%$ of the patients over the age of 40 year: $29.2 \%$ of the patients had hernias, $81.5 \%$ had facet degeneration and $48.1 \%$ had stenosis. Thus, these authors reported that, as with MRI, CT should not be the sole examination method. In symptomatic patients, an area of $100 \mathrm{~mm}^{2}$ or less in the region of the dural sac viewed axially was correlated with stenosis. However, Steurer et al reported that the measurement most used to establish the diagnosis of stenosis of the canal was an anteroposterior diameter of less than $10 \mathrm{~mm}$ with an area of less than $70 \mathrm{~mm}^{2}$. The authors concluded that there was a need for a consensus to define measurements, along with non-ambiguous radiographic criteria, in order to improve the accuracy of the diagnosis ${ }^{(20)}$.

\section{Electroneuromyography}

Patients who present symptoms and have physical and imaging examination results compatible with lumbar stenosis do not require additional examinations. Electroneuromyography (ENMG) is recommended when the diagnosis of neuropathy is controversial, especially in relation to patients with diabetes mellitus $^{(1,4,5,17)}$.

\section{Conservative treatment}

The symptoms of stenosis generally respond well to conservative treatment, even among patients with incapacitating pain, radiculopathy, myelopathy and claudication. The treatment should include resting for two days, analgesia, anti-inflammatory drugs and physiotherapy. Traction has not been proven to be beneficial $^{(4)}$. However, it should be emphasized that conservative treatment does not alter the natural history of degenerative stenosis ${ }^{(6)}$.

For patients who do not present regression of the symptoms of radiculopathy or neurogenic claudication, injections of epidural steroids can be used, although there are no well-documented long-term studies on the efficacy of such treatment ${ }^{(4)}$. The systematic reviews on the use of epidural injections that have been conducted are confusing and generally mix together different syndromes (radiculopathy, stenosis, pain of disc origin, etc), different techniques (use of fluoroscopy, interlaminar injections, caudal injections or transforaminal-periradicular injections), or both. The results from using epidural injections of corticoids to treat lumbar stenosis have generally been limited ${ }^{(3)}$.

Simotas et $\mathrm{al}^{(21)}$ presented a study using a conservative treatment and observed that after three years of follow-up, only $18 \%$ of the patients required a surgical procedure. Johnsson et $\mathrm{al}^{(22)}$ observed that $70 \%$ of the patients with untreated stenosis (anteroposterior diameter $>11 \mathrm{~mm}$ ) still did not show any abnormalities after four years of follow-up: $15 \%$ showed improvements and $15 \%$ worsened. Atlas et $\mathrm{al}^{(23)}$ observed that $50 \%$ of their patients who were treated conservatively presented improvements with regard to lumbalgia and irradiation after eight to ten years.

Amundsen et $\mathrm{al}^{(11)}$ highlighted that it is uncommon for patients to develop cauda equina syndrome during conservative treatment. This suggests that delays in performing surgery are not associated with a worse prognosis.

\section{Surgical treatment}

In the absence of improvements in symptoms through conservative treatment, surgery is indicated in order to improve the patient's quality of life ${ }^{(6)}$. Decompression of the lumbar stenosis is often associated with correction of the adjacent instability, and this is the surgical procedure that is most frequently performed in adults over the age of 65 years $^{(2,24-26)}$. The indications for surgical procedures vary greatly in the literature. The main surgical indication for treating stenosis is for patients who do not improve with conservative treatment or even show worsening of their symptoms. The improvement in pain may be incomplete, ranging from 64 to $91 \%$. Guigui et al ${ }^{(27)}$ showed that there was only a $30 \%$ improvement in motor symptoms following laminectomy, and 58\% of the patients continued to present strength of grade four or five after three years of follow-up. The reoperation rates ranged from 6 to $23 \%$.

Among the new technologies that exist for treating stenosis of the canal are interspinous implants. It has been well-established that using these implants may induce an improvement in the patient's clinical condition, in relation to pain, function, quality of life and 
personal satisfaction. Anderson et al ${ }^{(28)}$ observed that there was a significant improvement over the first six weeks and that these improvements were maintained for up to two years of follow-up. The results presented by these authors favored use of the implant over conservative treatment, and may be extended to patients with or without grade I spondylolisthesis. In their study, it was observed that the radiographic examinations were not predictors for the result.

The studies comparing surgical treatment with conservative treatment have presented limited numbers of patients and have involved individuals with and without degenerative spondylolisthesis in the same study. Amundsen et $\mathrm{al}^{(11)}$ observed that the results from conservative treatment worsened over time, but that if the surgical procedure was performed not more than three years after the treatment started, the results were not worse, and there was no deterioration over the first six years of follow-up. These authors suggested that conservative treatment would be appropriate for pain that was considered to be moderate, with a $50 \%$ improvement within three months. Worsening of the symptoms after appropriate conservative treatment was an indication for surgical treatment.

Herno et $\mathrm{al}^{(29)}$ evaluated 191 patients after four years of postoperative follow-up and observed that $64 \%$ of them presented stenosis of the vertebral canal. Small differences were observed between patients with and without stenosis regarding the clinical criteria, but there were no differences regarding the distances that they covered while walking. Instability was seen in $21 \%$, without clinical abnormalities, and the degree of decompression, as assessed using myelotomography, did not correlate with the results. However, Surin et $\mathrm{al}^{(30)}$ presented discordant results.

Kovacs et al ${ }^{(31)}$ conducted a systematic review of conservative and surgical treatment for lumbar stenosis. Surgery presented better results in relation to pain and quality of life, with changes regarding walking. However, the best results occurred during the interval from three months to two to four years, and they became close to the results from conservative treatment after this time.

Weinstein et $\mathrm{al}^{(2)}$ reported that patients with stenosis confirmed through imaging examinations without the presence of spondylolisthesis, who had presented symptoms in their lower limbs for more than 12 weeks, surgery was superior to conservative treatment with regard to symptom relief and functional improvement, and that this persisted for two years. The reintervention rates ranged from 1 to $2 \%$ for one year of follow-up. The complication rates were between 12 and 14\%, and complications were more frequent with increasing age and with greater numbers of comorbidities.

The prognostic factors for better outcomes have still not been well identified ${ }^{(26)}$. However, some authors have reported good prognoses for stenosis due to disc hernia, stenosis only one level, loss of strength lasting for less than six weeks, monoradiculopathy and age less than 65 years $^{(4)}$. Athiviraham et $\mathrm{al}^{(26)}$ reported that operated patients presented better results for two years of follow-up. These authors observed that body mass index and histories of psychiatric disease were factors associated with a poor prognosis, and that age, sex, cardiological comorbidities, musculoskeletal comorbidities, duration of symptoms longer than one year, decompression at multiple levels, fusion, neurogenic claudication, symptoms extending to the lumbosacral spine, weakness and diminished reflexes and sensitivity were not associated with a poor prognosis. They concluded that, on average, patients undergoing surgical procedures presented better results.

Weinstein et $\mathrm{al}^{(32)}$ highlighted that patients who underwent decompression with or without arthrodesis presented perioperative complication rates ranging from $5.4 \%$ to $14 \%$, and that most of these were in relation to lesions of the dura mater. During the postoperative period, the complication rate was between $8.2 \%$ and $18 \%$. The numbers of deaths were similar for conservative and surgical treatments. The reoperation rates were of the order of $1.3 \%$ to $2 \%$ in the first year and $6 \%$ to $11 \%$ in the second year, and reached $15 \%$ in the fourth year.

\section{CONCLUSIONS}

Degenerative lumbar stenosis is a frequent diagnosis among elderly patients. Anamnesis and physical examination are fundamental for assessing this pathological condition. Radiographic examination provides indirect signs and, therefore, MRI may be requested if the symptoms persist. There is still some controversy regarding the treatment for lumbar stenosis. Cohort studies with longer follow-ups are still necessary. 


\section{REFERENCES}

1. Aebi M, Gunzburg S, Szpalski S. The aging spine. Germany: Springer; 2005

2. Weinstein JN, Tosteson TD, Lurie JD, Tosteson ANA, Blood E, Hanscom B, et al. Surgical versus nonsurgical therapy for lumbar spinal stenosis. $\mathrm{N}$ Engl J Med. 2008;358(8):794-810.

3. Genevay S, Atlas SJ. Lumbar spinal stenosis. Best Pract Res Clin Rheumatol. 2010;24(2):253-5.

4. Curlee PM. Other disorders of the spine: Spine stenosis. In: Canale ST, Beatty $\mathrm{JH}$, editors. Campbell's operative orthopaedics. 11th. Mosby Elsevier: Philadelphia; 2007. p. 2274-87.

5. Joaquim AF, Sansur CA, Hamilton DK, Shaffrey Cl. Degenerative lumbar stenosis. Arq Neuropsiquiatr. 2009;67(2-B):553-8.

6. Zingg POZ, Boos N. Lumbar spinal stenosis. In: Boss N, Aebi M, editors Disorders of the spine. Berlin: Springer-Verlag Heidelberg; 2008. p. 513-33

7. Dunlop RB, Adams MA, Hutton WC. Disc space narrowing and lumbar facet joints. J Bone Joint Surg Br. 1984;66(5):706-10

8. Ciric I, Mikhael MA, Tarkington JA, Vick NA. The lateral recess syndrome: a variant of the spinal stenosis. J Neurosurg. 1980;53(4):433-43.

9. Schonstrom N, Lindahl S, Willen J, Hansson T. Dynamic changes in the dimensions of the lumbar spinal canal: an experimental study in vitro. J Orthop Res. 1989;7(1):115-21.

10. Inufusa A, An HS, Lim TH, Hasegawa T, Haughton VM, Nowicki BH. Anatomic changes of the spinal canal and intervertebral foramen associated with flexion-extension movement. Spine (Phila Pa 1976). 1996;21(21):2412-20.

11. Amundsen $T$, Weber $H$, Nordal HJ, Magnaes $B$, Abdelnoor M, Lilleas F. Lumbar spinal stenosis: conservative or surgical management? A prospective 10-year study. Spine (Phila Pa 1976).2000;25:1424-36.

12. Videman T, Nurminen M, Troup JDG. Lumbar spinal pathology in cadaveric material in relation to history of back pain, occupation and physical loading. Spine (Phila Pa 1976). 1990;15(8):728-40.

13. Miller JAA, Schmatz $C$, Schultz AB. Lumbar disc degeneration: correlation with age, sex and spine levels in 600 autopsy specimens. Spine (Phila Pa 1976). 1988;13(2):173-8.

14. Punjabi MM. Clinical spinal instability and low back pain. J Electro Kines. 2003;13:371-379.

15. Jarvik JG, Deyo RA. Diagnostic evaluation of low back pain with emphasis on imaging. Ann Inter Med. 2002;137(7):586-97.

16. Boden SD, Davis DO, Dina TS, Petronas NJ, Wiesel SW. Abnormal magnetic-resonance scans of the lumbar spine in asymptomatic subjects. J Bone Joint Surg Am. 1990;72(3):403-8

17. NASS. Diagnosis and treatment of degenerative lumbar spinal stenosis. North American Spine Society: Evidence-based clinical guidelines for multidisciplinary spine care; 2007
18. Eun SS, Lee HY, Lee SH, Kim KH, Liu WC. MRI versus CT for the diagnosis of lumbar spinal stenosis. J Neuroradiol 2011. [Epub ahead of print].

19. Wiesel SW, Tsourmas N, Feffer HL, Citrin CM, Patronas N. A study of computer-assisted tomography. I. the incidence of positive CAT scans in an symptomatic group of patients. Spine (Phila Pa 1976). 1984;9(6):549-51.

20. Steurer J, Roner S, Gnannt R, Hodler J. Quantitative radiologic criteria for the diagnosis of lumbar spinal stenosis: a systematic literature review. BMC Musculoskelet Disord. 2011;12(1):175.

21. Simotas AC, Dorey FJ, Hansraj KK, Cammisa F Jr. Nonoperative treatment for lumbar stenosis: clinical and outcome results and a 3-year survivorship analysis. Spine (Phila Pa 1976). 2000;25(2):197-203.

22. Johnsson K, Udén A, Rosén I. The effect of decompression on the natural course of spinal stenosis: a comparison of surgically treated and untreated patients. Spine (Phila Pa 1976). 1991;16(6):615-9.

23. Atlas SJ, Keller RB, Wu Ya, Deyo RA, Singer DE. Long-term outcomes of surgical and nonsurgical management of lumbar spinal stenosis: 8 to 10 year results from the Maine lumbar spine study. Spine (Phila Pa 1976). 2005;30(8):936-43.

24. Deyo RA, Ciol MA, Cherkin DC, Loeser JD, Bigos SJ. Lumbar spinal fusion: a cohort study of complications, reoperations, and resource use in the medicare population. Spine (Phila Pa 1976). 1993;18(11):1463-70

25. Deyo RA, Gray DT, Kreuter W, Mirza S, Martin BI. United States trends in lumbar fusion surgery for degenerative conditions. Spine (Phila Pa 1976). 30(12):1441-5.

26. Athiviraham A, Wali ZA, Yen D. Predictive factors influencing clinical outcome with operative management of lumbar spinal stenosis. Spine J. 2011;11(7):613-7.

27. Guigui P, Benoist M, Delecourt C, Delhoume J, Deburge A. Motor deficit in lumbar spinal stenosis: a retrospective study of a series of 50 patients. J Spinal Disord. 1998;11(4):283-8

28. Anderson PA, Tribus CB, Kitchel SH. Treatment of neurogenic claudication by interspinous decompression: application of the X STOP device in patients with lumbar degenerative spondylolisthesis. J Neurosurg Spine. 2006;4(6):463-71.

29. Herno A, Airaksinen O, Saari T, Pitkanen M, Manninen H, Suomalainen O. Computed tomography findings 4 years after surgical management of lumbar stenosis: no correlation with clinical outcome. Spine (Phila Pa 1976). 1999;24(21):2234-9

30. Surin V, Hedelin E, Smith L. Degenerative lumbar spinal stenosis: results of operative treatment. Acta Orthop Scand. 1982;53(1):79-85

31. Kovacs FM, Urrutia G, Alarcón JD. Surgery versus conservative treatment for symptomatic lumbar spinal stenosis: a systematic review of randomized controlled trials. Spine (Phila Pa 1976). 2011;36(20):E1335-51.

32. Weinstein JN, Lurie JD, Tosteson TD, Hanscom B, Tosteson AN, Blood EA, et al. Surgical versus nonsurgical treatment for lumbar degenerative spondylolisthesis. N Engl J Med 2007;356(22):2257-70 